\title{
Soybean Cyst Nematode Reproduction in the North Central United States
}

J. Wang, P. A. Donald, and T. L. Niblack, Department of Plant Pathology, University of Missouri, Columbia 65211; G. W. Bird, Department of Entomology, Michigan State University, East Lansing 48824; J. Faghihi and J. M. Ferris, Department of Entomology, Purdue University, West Lafayette 47907; C. Grau, Department of Plant Pathology, University of Wisconsin, Madison 53706; D. J. Jardine, Department of Plant Pathology, Kansas State University, Manhattan 66506; P. E. Lipps, Department of Plant Pathology, Ohio State University, Columbus 43210; A. E. MacGuidwin, Department of Plant Pathology, University of Wisconsin; H. Melakeberhan, Department of Entomology, Michigan State University; G. R. Noel, USDA ARS, Crop Protection Research Unit and Department of Crop Sciences, University of Illinois, Urbana 61801; P. Pierson and R. M. Riedel, Department of Plant Pathology, Ohio State University; P. R. Sellers, Department of Botany and Plant Pathology, Purdue University; W. C. Stienstra, Department of Plant Pathology, University of Minnesota, St. Paul 55108; T. C. Todd, Department of Plant Pathology, Kansas State University; G. L. Tylka, Department of Plant Pathology, Iowa State University, Ames 50011; T. A. Wheeler, Department of Plant Pathology, Ohio State University; and D. S. Wysong, Department of Plant Pathology, University of Nebraska, Lincoln 68583

\begin{abstract}
Wang, J., Donald, P. A., Niblack, T. L., Bird, G. W., Faghihi, J., Ferris, J. M., Grau, C., Jardine, D. J., Lipps, P. E., MacGuidwin, A. E., Melakeberhan, H., Noel, G. R., Pierson, P., Riedel, R. M., Sellers, P. R., Stienstra, W. C., Todd, T. C., Tylka, G. L., Wheeler, T. A., and Wysong, D. S. 2000. Soybean cyst nematode reproduction in the north central United States. Plant Dis. 84:77-82.

An experiment was conducted in Heterodera glycines-infested fields in 40 north central U.S. environments (21 sites in 1994 and 19 sites in 1995) to assess reproduction of this nematode. Two resistant and two susceptible soybean cultivars from each of the maturity groups (MG) I through IV were grown at each site in $6.1 \mathrm{~m}$ by 4 row plots. Soil samples were collected from each plot at planting and harvest and processed at Iowa State University to determine H. glycines initial $(\mathrm{Pi})$ and final $(\mathrm{Pf})$ population densities as eggs per $100 \mathrm{~cm}^{3}$ of soil. Overall, reproduction (Pf/Pi) of $H$. glycines on susceptible cultivars in all MG was similar. Reproduction was higher on MG III and IV susceptible cultivars than on those in MG I and II. Resistant MG I and II cultivars reduced nematode population densities more consistently than those in MG III and IV. Reproduction of the nematode was similar among sites within the same maturity zone (MZ), defined as the areas of best adaptation of the corresponding MG. Nonetheless, careful monitoring of nematode population densities is necessary to assess changes that occur over time in individual fields.
\end{abstract}

Additional keywords: Glycine max, soybean maturity group, soybean maturity zone
The soybean cyst nematode, Heterodera glycines, is an economically important pathogen of soybean, Glycine max, in the north central region where most U.S. soybeans are produced (3). In six north central states (Illinois, Indiana, Iowa, Minnesota, Missouri, and Ohio) surveyed for the presence of $H$. glycines, 47 to $83 \%$ of soybean hectarage was found to be infested (13). One estimate of the soybean crop loss in

Corresponding author: T. L. Niblack

E-mail: niblackt@missouri.edu

Current address of P. Pierson: DeKalb Genetics Corporation, 3100 Sycamore Road, DeKalb, IL 60115.

Current address of T. A. Wheeler: Texas Agriculture Experimental Station, Rt. 3, Box 219, Lubbock 79401 .

Accepted for publication 29 September 1999.

Publication no. D-1999-1112-01R

(C) 2000 The American Phytopathological Society north central states attributable to $H$. glycines parasitism was over $\$ 200$ million annually (2). Significant yield losses can occur in the absence of aboveground symptoms (7), which delayed recognition of the extent of the problem in this region until the last decade. Recommendations for soybean management tactics in $H$. glycines-infested fields vary from state to state, but all have in common the use of resistant soybean cultivars as the first and most effective option (8). Nonetheless, $H$. glycines continues to spread, and development of resistant cultivars and other effective control options remains a priority.

Interactions between field populations of H. glycines and soybean cultivars within maturity groups adapted to the north central states have not been described. Consequently, a group of plant pathologists and nematologists from 10 north central states investigated the effects of soybean maturity group, resistance to $H$. glycines, and environment on the reproduction of $H$. glycines.

\section{MATERIALS AND METHODS}

Two H. glycines-resistant and two susceptible cultivars from each of four matur-
Table 1. Characteristics of soybean cultivars grown in 40 environments in maturity zones 1 to 4 in 1994 and 1995

\begin{tabular}{lccc}
\hline Cultivar & Maturity group & ${\text { Reaction to H. } \text { glycines }^{\mathbf{y}}}$ & Source \\
\hline Parker & I & S & Public \\
Sturdy & I & S & Public \\
AP 1991 & I & R (Peking) & AgriPro \\
Bell & I & R (PI 88788) & Public \\
Corsoy 79 & II & S & Public \\
Kenwood & II & S (Peking) & Public \\
Newton & II & R (PI 88788) & Public \\
Jack & II & S & Public \\
Resnik & III & S & Public \\
Williams 82 & III & R (Peking) & Missouri Farmers Assoc. \\
MFA 9043z & III & R (PI 88788) & Public \\
Linford & III & S & Public \\
Flyer & IV & S & Public \\
Spencer & IV & R (Peking) & Public \\
Pharaoh & IV & R (PI 88788) & Public \\
Delsoy 4210 & IV & I H. glycines & \\
\hline
\end{tabular}

y $\mathrm{S}=$ susceptible to Heterodera glycines; $\mathrm{R}=$ resistant to $H$. glycines (source of resistance in parentheses). ${ }^{\text {z }}$ MFA 9045 was used in 1995. 
Table 2. Test sites, soil texture, initial population densities, maturity zones (MZ), planting dates, and race tests in 1994 and 1995

\begin{tabular}{|c|c|c|c|c|c|c|}
\hline Year & Test site & Soil texture & $\mathbf{P i}^{\mathbf{w}}$ & MZ & Planting date ${ }^{x}$ & Race test $^{y}$ \\
\hline \multirow[t]{21}{*}{1994} & St. Charles, MI $^{\mathrm{z}}$ & Sandy loam & 3,464 & 1,2 & $\ldots$ & $\ldots$ \\
\hline & Renville, MN & Clay loam & 454 & 1 & $\ldots$ & $\ldots$ \\
\hline & Jackson, MN & Loam & 1,172 & 1 & $\ldots$ & $\ldots$ \\
\hline & Hancock, WI & Sand & 4,294 & 1 & $\ldots$ & $\ldots$ \\
\hline & Kanawha, IA & Clay loam & 1,293 & 2 & May 9 & $\ldots$ \\
\hline & Crawfordsville, IA & Clay loam & 539 & 2 & May 19 & $\ldots$ \\
\hline & Ames, IA & Clay loam & 3,998 & 2 & $\ldots$ & $\ldots$ \\
\hline & Dowagiac, MI & Loamy sand & 4,287 & 2 & $\ldots$ & $\ldots$ \\
\hline & Tekamah, NE & Clay loam & 5,112 & 2 & $\ldots$ & 3 \\
\hline & Tekamah, NE & Loam & 5,500 & 2 & $\ldots$ & 3 \\
\hline & Racine, WI & Clay loam & 2,377 & 2 & $\ldots$ & 3 \\
\hline & Champaign, IL & Loam & 263 & 3 & May 19 & $\ldots$ \\
\hline & Champaign, IL & Silt loam & 944 & 3 & May 20 & 9 \\
\hline & Lafayette, IN & Silt loam & 454 & 3 & $\ldots$ & 3 \\
\hline & Romney, IN & Silt loam & 1,032 & 3 & $\ldots$ & 6 \\
\hline & Severance, KS & Silt loam & 369 & 3 & May 13 & 3 \\
\hline & Benton City, MO & Silt loam & 2,058 & 3 & $\ldots$ & $\ldots$ \\
\hline & Edina, $\mathrm{MO}$ & Silt loam & 2,316 & 3 & $\ldots$ & $\ldots$ \\
\hline & Mt. Sterling, $\mathrm{OH}$ & Clay loam & 3,995 & 3 & May 12 & 14 \\
\hline & Bucyrus, $\mathrm{OH}$ & Silty clay loam & 8,519 & 3 & May 5 & 9 \\
\hline & Columbus, KS & Loam & 1,482 & 4 & June 10 & 3 \\
\hline \multirow[t]{21}{*}{1995} & St. Charles, MIz & Sandy loam & 5,677 & 1,2 & May 18 & $\ldots$ \\
\hline & St. Charles, MI & Sandy loam & 4,078 & 1,2 & May 18 & 3 \\
\hline & Sacred Heart, MN & Clay loam & 605 & 1 & May 30 & $\ldots$ \\
\hline & Lake Crystal, MN & Clay loam & 824 & 1 & $\ldots$ & $\ldots$ \\
\hline & Kanawha, IA & Clay loam & 3,208 & 2 & May 12 & $\ldots$ \\
\hline & Muscatine, IA & Loamy sand & 10,110 & 2 & May 19 & 3 \\
\hline & Ames, IA & Loam & 2,180 & 2 & $\ldots$ & $\ldots$ \\
\hline & Dwight, IL & Loam & 1,664 & 2 & $\ldots$ & 5 \\
\hline & Tekamah, NE & Loam & 15,220 & 2 & June 16 & $\ldots$ \\
\hline & Tekamah, NE & Silty clay loam & 10,102 & 2 & June 16 & $\ldots$ \\
\hline & Jerry City, OH & Sandy loam & 4,399 & 2 & May 23 & 3 \\
\hline & Racine, WI & Clay loam & 1,162 & 2 & $\ldots$ & $\ldots$ \\
\hline & Champaign, IL & Silt loam & 216 & 3 & June 2 & 3 \\
\hline & Newton, IL & Loam & 29,765 & 3 & June 13 & 3 \\
\hline & Lafayette, IN & Silt loam & 3,294 & 3 & June 5 & 3 \\
\hline & Romney, IN & Loam & 6,036 & 3 & June 6 & 6 \\
\hline & Rossville, KS & Sandy loam & 11,970 & 3 & May 16 & 14 \\
\hline & Benton City, MO & Silt loam & 5,855 & 3 & June 19 & $\ldots$ \\
\hline & Edina, MO & Silt loam & 6,110 & 3 & June 20 & $\ldots$ \\
\hline & West Milton, $\mathrm{OH}$ & Clay loam & 13,629 & 3 & June 8 & $\ldots$ \\
\hline & Columbus, KS & Silt loam & 4,803 & 4 & June 28 & 3 \\
\hline
\end{tabular}

${ }^{\mathrm{w}} \mathrm{Pi}=$ number of eggs of Heterodera glycines per $100 \mathrm{~cm}^{3}$ soil at planting.

x Planting dates are given when exact date is known; for those not given, plants were planted on locally recommended dates.

y Race testing was conducted by local cooperators according to various protocols.

${ }^{\mathrm{z}} \mathrm{St}$. Charles is located along the division line between maturity zones I and II. It was included in both maturity zones for analysis.

Table 3. Means of initial population (Pi) and reproduction (Rf) of the soybean cyst nematode on resistant and susceptible soybean cultivars within maturity zones (MZ) 1 to 4 in the north central region in 1994 and $1995^{\mathrm{v}}$

\begin{tabular}{|c|c|c|c|c|c|c|c|}
\hline \multirow[b]{2}{*}{ Yearw } & \multirow[b]{2}{*}{ MZ } & \multicolumn{3}{|c|}{ Resistant cultivars } & \multicolumn{3}{|c|}{ Susceptible cultivars } \\
\hline & & $\mathbf{P i}^{\mathbf{x}}$ & $\mathbf{R f}^{y}$ & $\mathbf{N}^{\mathbf{z}}$ & $\mathbf{P i}$ & Rf & $\mathbf{N}$ \\
\hline \multirow[t]{4}{*}{1994} & 1 & $631 \mathrm{~b}$ & $0.62 \mathrm{a}$ & 126 & $871 \mathrm{~b}$ & $7.59 \mathrm{~b}$ & 126 \\
\hline & 2 & $1,380 \mathrm{a}$ & $0.66 \mathrm{a}$ & 253 & $1,380 \mathrm{a}$ & $5.25 \mathrm{~b}$ & 253 \\
\hline & 3 & $364 \mathrm{c}$ & $1.12 \mathrm{a}$ & 286 & $468 \mathrm{c}$ & $6.03 \mathrm{~b}$ & 283 \\
\hline & 4 & $661 \mathrm{abc}$ & $1.15 \mathrm{a}$ & 32 & $661 \mathrm{abc}$ & $43.65 \mathrm{a}$ & 32 \\
\hline \multirow[t]{3}{*}{1995} & 1 & 832 b & $0.81 \mathrm{a}$ & 128 & $851 \mathrm{~b}$ & $5.37 \mathrm{a}$ & 127 \\
\hline & 2 & $3,162 \mathrm{a}$ & $0.48 \mathrm{bc}$ & 285 & $2,951 \mathrm{a}$ & $2.34 \mathrm{~b}$ & 287 \\
\hline & 3 & $2,512 \mathrm{a}$ & $0.34 \mathrm{c}$ & 244 & $3,236 \mathrm{a}$ & $1.91 \mathrm{~b}$ & 247 \\
\hline
\end{tabular}

$\vec{v}$ All data were transformed to $\log 10(\mathrm{Pi}+1)$ values for Pi or $\log 10[(\mathrm{Pf}+1) /(\mathrm{Pi}+1)]$ values for Rf before analysis. Means of non-transformed Pi or Rf are presented for clarity. Mean separation was performed with the least-squares means (LSMEANS) option of the general linear models (GLM) procedure of SAS. Means followed by the same letter within columns and the same year are not significantly different at $P=0.05$. Number of sites in each maturity zone from 1 to 4 were $4,8,9$, and 1 in 1994; from zone 1 to 3 were 4,9 , and 8 in 1995 .

${ }^{\mathrm{w}} F$ values of the 2 years: $F_{\mathrm{Pi}}=0.5973 / 0.2192=2.725, F_{\mathrm{Rf}}=0.7331 / 0.3930=1.865\left(P_{0.05}=1.0\right)$.

${ }^{\mathrm{x}} \mathrm{Pi}=$ number of eggs per $100 \mathrm{~cm}^{3}$ of soil at planting.

${ }^{y} \mathrm{Rf}=(\mathrm{Pf}+1) /(\mathrm{Pi}+1)$, where $\mathrm{Pf}$ is the number of eggs per $100 \mathrm{~cm}^{3}$ of soil at or near harvest, and Pi is the number of eggs per $100 \mathrm{~cm}^{3}$ of soil at planting.

z Total number of observations. Only sites with complete data sets (four maturity groups at any site) were included for analysis. 
ity groups (MG I through IV) (Table 1) were grown at each location in 1994 and 1995. Plots consisted of mostly mediumtextured soil (loam, silt loam, clay loam, and silty loam) in both years (Table 2). Experimental locations were distributed within maturity zones (MZ) 1 to 4 in 10 states. MZ 1 to 4 are the geographic zones of best adaptation of the soybean MG I to
IV, respectively. All field plots were naturally infested with $H$. glycines. Seeds were planted during the appropriate period for commercial soybean production at each location. Weed control at each location was accomplished with traditionally recommended herbicides and/or cultivation.

At every location, individual plots consisted of four 6.1-m-long rows spaced 76

Table 4. Analysis of variance for reproduction (Rf) of the soybean cyst nematode in the north central region in $1995^{\mathrm{y}}$

\begin{tabular}{lrcl}
\hline Source $^{\mathbf{z}}$ & df & Sum of squares & $\boldsymbol{P r}>\boldsymbol{F}$ \\
\hline MZ & 3 & 30.50 & 0.0001 \\
Site $(\mathrm{MZ})$ & 19 & 157.50 & 0.0001 \\
Rep $(\mathrm{MZ} \times$ site) & 68 & 44.00 & 0.0009 \\
Res & 1 & 163.51 & 0.0001 \\
MZ $\times$ res & 3 & 3.02 & 0.0533 \\
MG & 3 & 7.40 & 0.0003 \\
MZ $\times$ MG & 8 & 2.77 & 0.5290 \\
MG $\times$ res & 3 & 0.77 & 0.5828 \\
MZ $\times$ MG $\times$ res & 8 & 5.31 & 0.0957 \\
CV $($ MG $\times$ res) & 8 & 3.14 & 0.4336 \\
Site $\times$ res (MZ) & 19 & 55.52 & 0.0001 \\
Site $\times$ MG $($ MZ) & 55 & 24.78 & 0.2166 \\
Site $\times$ MG $\times$ res $(M Z)$ & 55 & 26.22 & 0.1384
\end{tabular}

${ }^{y} \mathrm{Rf}=(\mathrm{Pf}+1) /(\mathrm{Pi}+1)$ where $\mathrm{Pf}$ is the number of eggs per $100 \mathrm{~cm}^{3}$ of soil at or near harvest, and $\mathrm{Pi}$ is the number of eggs per $100 \mathrm{~cm}^{3}$ soil at planting.

${ }^{\mathrm{z}}$ Sources of variance. $\mathrm{MZ}=$ maturity zone $(1,2,3,4)$, site $=$ test site, res = resistant type (resistant, susceptible), MG = maturity group (I, II, III, and IV), CV = tested cultivars listed in Table 1.

$\mathrm{cm}$ apart. Each cultivar was replicated four times in randomized complete blocks. Soil samples were taken at or shortly after planting but before any postplant cultivation for estimation of initial population densities (Pi) of $H$. glycines, and at or near harvest for final population densities $(\mathrm{Pf})$. Ten soil cores (19 $\mathrm{mm}$ diameter by 15 to $20 \mathrm{~cm}$ ) were collected in a zig-zag pattern from the center 4.9-m length of the two center rows. A composite sample from each plot was sent to Iowa State University for cyst extraction and egg enumeration. Cysts were extracted from $100 \mathrm{~cm}^{3}$ subsamples with a semiautomatic elutriator (1). Eggs were released from extracted cysts with a motorized pestle (7) and counted under a dissecting microscope. Race determination tests were conducted locally by some cooperators using various protocols (e.g., 7).

All nematode data were transformed to $\log 10(x+1)$ values before analysis to reduce the correlation between means and variances. The effects of year, MZ, site, MG, and cultivar resistance were evaluated by means of the general linear models (GLM) procedure of SAS (SAS Institute, Cary, NC). Means over MZ and MG were separated with least-squares estimates of

Table 5. Means of initial population (Pi) and reproduction (Rf) of the soybean cyst nematode on resistant and susceptible soybean cultivars of maturity groups (MG) I through IV in four maturity zones combined in the north central region in 1994 and $1995^{\mathrm{w}}$

\begin{tabular}{|c|c|c|c|c|c|c|c|}
\hline \multirow[b]{2}{*}{ Year } & \multirow[b]{2}{*}{ MG } & \multicolumn{3}{|c|}{ Resistant cultivars } & \multicolumn{3}{|c|}{ Susceptible cultivars } \\
\hline & & $\mathbf{P i}^{\mathbf{x}}$ & $\mathbf{R f}^{\mathbf{y}}$ & $\mathrm{N}^{\mathbf{z}}$ & $\mathbf{P i}$ & $\mathbf{R f}$ & $\mathbf{N}$ \\
\hline 1994 & $\begin{array}{l}\text { I } \\
\text { II } \\
\text { III } \\
\text { IV }\end{array}$ & $\begin{array}{l}724 a b \\
813 a \\
513 b \\
661 a b\end{array}$ & $\begin{array}{l}0.50 \mathrm{~b} \\
0.56 \mathrm{~b} \\
1.02 \mathrm{a} \\
1.10 \mathrm{a}\end{array}$ & $\begin{array}{l}175 \\
173 \\
174 \\
175\end{array}$ & $\begin{array}{l}813 \mathrm{a} \\
933 \mathrm{a} \\
676 \mathrm{a} \\
741 \mathrm{a}\end{array}$ & $\begin{array}{l}6.17 \mathrm{ab} \\
4.79 \mathrm{~b} \\
6.76 \mathrm{ab} \\
8.71 \mathrm{a}\end{array}$ & $\begin{array}{l}176 \\
176 \\
172 \\
170\end{array}$ \\
\hline 1995 & $\begin{array}{l}\text { I } \\
\text { II } \\
\text { III } \\
\text { IV }\end{array}$ & $\begin{array}{l}2,630 \mathrm{a} \\
2,344 \mathrm{ab} \\
1,950 \mathrm{~b} \\
2,399 \mathrm{ab}\end{array}$ & $\begin{array}{l}0.39 \mathrm{~b} \\
0.38 \mathrm{~b} \\
0.47 \mathrm{ab} \\
0.65 \mathrm{a}\end{array}$ & $\begin{array}{l}163 \\
166 \\
163 \\
165\end{array}$ & $\begin{array}{l}2,239 \mathrm{~b} \\
2,754 \mathrm{ab} \\
2,818 \mathrm{a} \\
2,399 \mathrm{ab}\end{array}$ & $\begin{array}{l}1.91 \mathrm{~b} \\
2.00 \mathrm{~b} \\
2.95 \mathrm{a} \\
3.24 \mathrm{a}\end{array}$ & $\begin{array}{l}166 \\
165 \\
164 \\
166\end{array}$ \\
\hline
\end{tabular}

${ }^{\mathrm{w}}$ All data were transformed to $\log 10(\mathrm{Pi}+1)$ values for $\mathrm{Pi}$ or $\log 10[(\mathrm{Pf}+1) /(\mathrm{Pi}+1)]$ values for $\mathrm{Rf}$ before analysis. Means of non-transformed Pi or Rf are presented for clarity. Means separation was performed with means (MEANS) option of the general linear models (GLM) procedure of SAS. Means followed by the same letter within columns and the same year are not significantly different at $P=0.05$. Number of sites in each zone from 1 to 4 were 4,8 , 9, and 1 in 1994 and 4, 10, 8, and 1 in 1995.

$\times \mathrm{Pi}=$ number of eggs per $100 \mathrm{~cm}^{3}$ of soil at planting.

${ }^{\mathrm{y}} \mathrm{Rf}=(\mathrm{Pf}+1) /(\mathrm{Pi}+1)$ where $\mathrm{Pf}$ is the number of eggs per $100 \mathrm{~cm}^{3}$ of soil at or near harvest, and $\mathrm{Pi}$ is the number of eggs per $100 \mathrm{~cm}^{3}$ of soil at planting.

${ }^{\mathrm{z}}$ Total number of observations.

Table 6. Means of reproduction (Rf) of the soybean cyst nematode on resistant and susceptible soybean cultivars of maturity groups (MG) I through IV within maturity zones (MZ) 1 to 4 in the north central region ${ }^{2}$

\begin{tabular}{|c|c|c|c|c|c|c|c|c|c|}
\hline \multirow[b]{2}{*}{ Year } & \multirow[b]{2}{*}{ MG } & \multicolumn{4}{|c|}{ Resistant cultivars } & \multicolumn{4}{|c|}{ Susceptible cultivars } \\
\hline & & MZ 1 & MZ 2 & MZ 3 & MZ 4 & MZ 1 & MZ 2 & MZ 3 & MZ 4 \\
\hline \multirow[t]{4}{*}{1994} & I & $0.34 \mathrm{~b}$ & $0.69 \mathrm{ab}$ & $0.47 \mathrm{~b}$ & $0.30 \mathrm{c}$ & $7.24 \mathrm{a}$ & $5.50 \mathrm{a}$ & $5.01 \mathrm{~b}$ & $69.18 \mathrm{a}$ \\
\hline & II & $0.59 \mathrm{ab}$ & $0.38 \mathrm{~b}$ & $0.79 a b$ & $0.32 b c$ & $6.92 \mathrm{a}$ & $3.98 \mathrm{a}$ & $4.07 \mathrm{~b}$ & $19.05 \mathrm{a}$ \\
\hline & III & $0.58 \mathrm{ab}$ & $0.98 \mathrm{a}$ & $1.32 \mathrm{a}$ & $2.34 \mathrm{ab}$ & $7.76 \mathrm{a}$ & $5.01 \mathrm{a}$ & $6.92 \mathrm{ab}$ & $38.90 \mathrm{a}$ \\
\hline & IV & $1.29 \mathrm{a}$ & $0.76 \mathrm{ab}$ & $1.26 \mathrm{a}$ & $2.57 \mathrm{a}$ & $8.32 \mathrm{a}$ & $7.08 \mathrm{a}$ & $9.33 \mathrm{a}$ & $70.79 \mathrm{a}$ \\
\hline \multirow[t]{4}{*}{1995} & I & $0.63 \mathrm{~b}$ & $0.46 \mathrm{a}$ & $0.26 \mathrm{~b}$ & $\ldots$ & $6.76 \mathrm{a}$ & $1.62 \mathrm{c}$ & $1.32 \mathrm{~b}$ & $\ldots$ \\
\hline & II & $0.65 \mathrm{~b}$ & $0.37 \mathrm{a}$ & $0.32 \mathrm{ab}$ & $\ldots$ & $5.38 \mathrm{a}$ & $2.00 \mathrm{bc}$ & $1.32 \mathrm{~b}$ & $\ldots$ \\
\hline & III & $0.76 \mathrm{ab}$ & $0.55 \mathrm{a}$ & $0.30 \mathrm{ab}$ & $\ldots$ & $5.75 \mathrm{a}$ & $2.82 \mathrm{ab}$ & $2.57 \mathrm{a}$ & $\ldots$ \\
\hline & IV & $1.48 \mathrm{a}$ & $0.56 \mathrm{a}$ & $0.51 \mathrm{a}$ & $\ldots$ & $3.80 \mathrm{a}$ & $3.31 \mathrm{a}$ & $3.16 \mathrm{a}$ & $\ldots$ \\
\hline
\end{tabular}

${ }^{\mathrm{z}} \mathrm{Rf}=(\mathrm{Pf}+1) /(\mathrm{Pi}+1)$, where $\mathrm{Pf}$ is the number of eggs per $100 \mathrm{~cm}^{3}$ of soil at or near harvest, and $\mathrm{Pi}$ is the number of eggs per $100 \mathrm{~cm}^{3}$ of soil at planting. All data were transformed to $\log 10[(\mathrm{Pf}+1) /(\mathrm{Pi}+1)]$ values before analysis. Means of nontransformed $\mathrm{Rf}$ are presented for clarity. Means separation was performed with the least-square means (LSMEANS) option of the general linear models (GLM) procedure of SAS. Means followed by the same letter within columns and the same year are not significantly different at $P=0.05$. Number of sites in each zone from 1 to 4 were $4,8,9$, and 1 in 1994 and 4 , 9, and 8 in 1995. Data were incomplete for MZ 4 in 1995. 
marginal means (LSMEANS) whenever possible. Relationships between reproduction $(\mathrm{Rf}$, defined as $[\mathrm{Pf}+1] /[\mathrm{Pi}+1])$ and $\mathrm{Pi}$ at each location were analyzed by regression. Parameters (slopes, intercepts) of linear models generated at any location were compared with those at other locations within the same MZ to test differences between those models.

\section{RESULTS}

$\mathrm{Pi}$ and $\mathrm{Rf}$ were different between the 2 years. Higher Pi and lower Rf occurred in 1995 than in 1994, especially in MZ 2 and 3 (Table 3). Analysis of variance indicated that the 2 years had heterogeneous variances $(P=0.05)$. Consequently, results from each year were analyzed separately. Reproduction of $H$. glycines was strongly influenced by local environments represented by site, MZ, their combinations, and soybean MG; however, interactions between MG and MZ were not significant in either year (Table 4; 1994 data not shown).
Reproduction on MG I to IV cultivars. In 1994, cultivars in MG III and IV supported greater $H$. glycines reproduction than those in MG I and II (Table 5). In MZ 1 , resistant cultivars in MG I through III suppressed $H$. glycines reproduction ( Rf < 1.0), whereas those in MG IV did not. MG I cultivars were the most effective in reducing $H$. glycines population densities (Table 6). In MZ 2, all resistant cultivars reduced $H$. glycines reproduction, with the greatest reduction on cultivars in MG II. In MZ 3, resistant cultivars in MG I and II suppressed $H$. glycines reproduction, but cultivars in MG III and IV allowed population densities to increase. The differences in $H$. glycines reproduction on resistant cultivars between MG I and II versus MG III and IV were also observed in MZ 4. Reproduction on susceptible cultivars in MG I, II, III, and IV was similar within each MZ (Table 6). The average Pf on all susceptible cultivars was considerably higher than Pi in MZ 4.
In 1995, cultivars in MG III and IV similarly supported greater $H$. glycines reproduction than those in MG I and II, although overall $\mathrm{Pi}$ values were 2.8 to 4.1 times greater in 1995 than in 1994 (Table 5). In MZ 1, all resistant cultivars reduced $H$. glycines reproduction except those in MG IV; however, the reduction was less than that in 1994 (Table 6). All susceptible cultivars supported increases in $H$. glycines population densities. Susceptible cultivars in MG III and IV supported greater $H$. glycines reproduction in MZ 2 and 3 than in MZ 1 (Table 6).

Relationships between $P i$ and reproduction (Rf). Reproduction was influenced by local environment (MZ and site) (Table 4); however, relationships between $\mathrm{Pi}$ and reproduction were similar regardless of locality (Table 7). Thirty-three of $40 \mathrm{Rf}$ on Pi regressions $(82.5 \%)$ were inverse for resistant cultivars. For susceptible cultivars, 38 of $40(95 \%)$ were inverse. Slopes of regressions ranged from -0.44

Table 7. Regression of Heterodera glycines reproduction (Rf) on initial nematode population density (Pi) at tested sites in soybean maturity zones (MZ) 1, 2 , and 3 in 1994 and $1995^{z}$

\begin{tabular}{|c|c|c|c|c|c|c|c|c|}
\hline \multirow[b]{2}{*}{ Year } & \multirow[b]{2}{*}{ MZ } & \multirow[b]{2}{*}{ Test site } & \multicolumn{3}{|c|}{ Resistant } & \multicolumn{3}{|c|}{ Susceptible } \\
\hline & & & Slope & Int. & $\mathbf{R}^{2}$ & Slope & Int. & $\mathbf{R}^{2}$ \\
\hline \multirow[t]{20}{*}{1994} & 1 & St. Charles, MI & NS & NS & NS & -0.77 & 3.20 & 0.59 \\
\hline & 1 & Renville, MN & -0.75 & 0.65 & 0.30 & -0.59 & 2.42 & 0.50 \\
\hline & 1 & Jackson, MN & -0.75 & 1.60 & 0.23 & NS & NS & NS \\
\hline & 1 & Hancock, WI & -0.87 & 0.28 & 0.41 & -0.98 & 4.19 & 0.84 \\
\hline & 2 & Kanawha, IA & -0.63 & 1.82 & 0.33 & -0.89 & 3.39 & 0.73 \\
\hline & 2 & Crawfordsville, IA & -0.54 & 1.12 & 0.27 & -0.43 & 1.99 & 0.18 \\
\hline & 2 & Ames, IA & -1.00 & 3.36 & 0.51 & -1.06 & 4.69 & 0.47 \\
\hline & 2 & Dowagiac, MI & -0.73 & 2.21 & 0.37 & -1.04 & 3.69 & 0.66 \\
\hline & 2 & Tekamah, NE & -0.93 & 3.32 & 0.41 & -0.98 & 4.16 & 0.56 \\
\hline & 2 & Tekamah, NE & -0.47 & 1.59 & 0.28 & -0.47 & 1.59 & 0.28 \\
\hline & 2 & Racine, WI & -1.83 & 4.97 & 0.22 & -0.88 & 3.49 & 0.36 \\
\hline & 3 & Champaign, IL & -0.56 & 0.78 & 0.14 & -0.83 & 2.39 & 0.43 \\
\hline & 3 & Champaign, IL & -1.24 & 4.00 & 0.24 & -1.19 & 4.13 & 0.28 \\
\hline & 3 & Lafayette, IN & -0.55 & 0.98 & 0.34 & -0.68 & 2.59 & 0.77 \\
\hline & 3 & Romney, IN & -0.97 & 3.15 & 0.82 & -0.75 & 3.49 & 0.83 \\
\hline & 3 & Severance, KS & -0.95 & 1.98 & 0.60 & -1.07 & 3.86 & 0.86 \\
\hline & 3 & Benton City, MO & -0.60 & 1.35 & 0.27 & -1.12 & 3.59 & 0.61 \\
\hline & 3 & Edina, MO & -1.10 & 3.27 & 0.30 & -1.40 & 5.26 & 0.58 \\
\hline & 3 & Mt. Sterling, $\mathrm{OH}$ & -0.58 & 1.32 & 0.48 & -0.89 & 2.89 & 0.86 \\
\hline & 3 & Bucyrus, $\mathrm{OH}$ & NS & NS & NS & -0.77 & 2.53 & 0.17 \\
\hline \multirow[t]{20}{*}{1995} & 1 & St. Charles, MI & -1.28 & 4.23 & 0.51 & -1.04 & 4.18 & 0.52 \\
\hline & 1 & St. Charles, MI & -0.95 & 3.15 & 0.57 & -0.88 & 3.43 & 0.46 \\
\hline & 1 & Sacred Heart, MN & -1.05 & 2.36 & 0.50 & -1.04 & 3.37 & 0.84 \\
\hline & 1 & Lake Crystal, MN & -1.02 & 2.58 & 0.56 & -1.25 & 4.21 & 0.65 \\
\hline & 2 & Kanawha, IA & -1.04 & 2.89 & 0.59 & -0.80 & 2.66 & 0.51 \\
\hline & 2 & Muscatine, IA & -0.44 & 0.70 & 0.13 & -1.27 & 4.56 & 0.51 \\
\hline & 2 & Ames, IA & NS & NS & NS & -0.96 & 3.93 & 0.43 \\
\hline & 2 & Dwight, IL & NS & NS & NS & -1.19 & 4.17 & 0.61 \\
\hline & 2 & Tekamah, NE & -0.60 & 2.09 & 0.26 & -0.63 & 2.53 & 0.35 \\
\hline & 2 & Tekamah, NE & -0.53 & 1.90 & 0.23 & -1.01 & 4.09 & 0.64 \\
\hline & 2 & Jerry City, OH & -0.52 & 1.26 & 0.17 & -0.70 & 3.35 & 0.35 \\
\hline & 2 & Racine, WI & -0.85 & 2.28 & 0.21 & -0.65 & 2.44 & 0.14 \\
\hline & 3 & Champaign, IL & -1.09 & 1.97 & 0.64 & -0.84 & 3.13 & 0.56 \\
\hline & 3 & Newton, IL & -0.95 & 3.38 & 0.25 & NS & NS & NS \\
\hline & 3 & Lafayette, IN & -0.48 & 1.33 & 0.21 & -0.68 & 2.79 & 0.71 \\
\hline & 3 & Romney, IN & -0.58 & 1.86 & 0.28 & -0.90 & 3.43 & 0.70 \\
\hline & 3 & Rossville, KS & NS & NS & NS & -1.22 & 4.61 & 0.28 \\
\hline & 3 & Benton City, MO & NS & NS & NS & -0.84 & 2.99 & 0.50 \\
\hline & 3 & Edina, $\mathrm{MO}$ & -0.51 & 1.73 & 0.23 & -0.71 & 2.62 & 0.34 \\
\hline & 3 & West Milton, $\mathrm{OH}$ & NS & NS & NS & -1.34 & 5.42 & 0.49 \\
\hline
\end{tabular}

${ }^{\mathrm{z}} \mathrm{Rf}=(\mathrm{Pf}+1) /(\mathrm{Pi}+1)$ where $\mathrm{Pf}$ is the number of eggs per $100 \mathrm{~cm}^{3}$ soil at or near harvest, and Pi is the number of eggs per $100 \mathrm{~cm}^{3}$ soil at planting . Regressions were performed on data transformed to $\log 10[(\mathrm{Pf}+1) /(\mathrm{Pi}+1)]$ values for $\mathrm{Rf}$ and $\log 10(\mathrm{Pi}+1)$ values for Pi. Param eters $\left(\mathrm{slopes,}\right.$, intercept, $\left.R^{2}\right)$ presented in the tables are for linear models which are significant at $P=0.05$. 
(Muscatine, IA, 1995) to -1.83 (Racine, WI, 1994) for resistant and from -0.43 (Crawfordsville, IA, 1994) to -1.40 (Edina, MO, 1994) for susceptible. Within the same MZ, slopes and intercepts derived from regression linear models were compared for each host reaction type (resistant and susceptible). Parameters for all locations were similar under the same host reaction type (Table 8). However, the regression model for resistant cultivars and that for susceptible cultivars within the same MZ were significantly different (Table 8).

\section{DISCUSSION}

Soybean MG influenced $H$. glycines reproduction in North Carolina, where MG $\mathrm{V}$ to VIII cultivars were tested (5). Cultivars in later MG tended to have a longer root growth period, which presumably provided additional time for nematode reproduction. The use of earlymaturing cultivars has been proposed for use in conjunction with other tactics for management of $H$. glycines in North Carolina $(6,11)$. In contrast, Todd (12) found little influence of soybean MG on $H$. glycines reproduction in MG III and IV cultivars tested in Kansas. In the present study, we observed that resistant cultivars of earlier MG appeared to be more effective in reducing nematode population density than those of later $\mathrm{MG}$ in all $\mathrm{MZ}$ tested. However, there were no significant differences in $\mathrm{Rf}$ on susceptible cultivars regardless of MG. The results suggest that although planting early-maturing resistant cultivars may reduce $H$. glycines $\mathrm{Rf}$ and $\mathrm{Pf}$, the benefit of reducing nematode reproduction is unlikely to be sufficient to overcome the economic effects of lower yields that early-maturing cultivars would probably have in higher MZ. Planting early-maturing cultivars that are susceptible to the nematode provides no benefits in reducing nematode population densities and may result in lower yields than similar later maturing cultivars.
Of particular interest in our data were increases in the nematode population on resistant cultivars observed in both years. Resistant cultivars in MG IV (Pharaoh, Delsoy 4210) were not effective in reducing $H$. glycines $\mathrm{Pf}$ in $\mathrm{MZ} 1$ in either year and in MZ 3 and 4 in 1994, although Pi were similar within MZ in both years. Similar results were observed with MG III resistant cultivars. In fact, increases in Pf were observed at more than half of all test sites where the resistant cultivars Linford, MFA 9043, Pharaoh, and Delsoy were planted in 1994. Linford has only a moderate level resistance to both race 3 and 4 in Illinois (9). Our results suggest that environmental factors play a significant role in regulating nematode reproduction on these cultivars. The genetic makeup of the nematode population at the test sites also may have affected our results. However, the results of race tests cannot be compared because the tests were conducted locally according to various protocols. Race test results can differ among labs, even when protocols are similar (10). Resistant cultivar-location specificity should be considered when recommendations for resistant cultivars are to be made. However, resistant cultivars in MG I and II were not influenced as much by factors associated with MZ as were resistant cultivars in MG III and IV.

Calculation of reproduction is used widely in nematology as an indicator of host status; higher reproduction rates are generally associated with more compatible interactions. Hosts are considered resistant if $\mathrm{Rf}<1.0$ where conducive environments for reproduction occur. By taking soil samples from the two center rows of each plot in this study, final populations were estimated from the stratum of maximum reproductive potential, due presumably to high root densities (4). Thus, Pf and Rf herein provide relative trends in many diverse environments. In addition, many factors other than host status and sampling can substantially affect Rf. Soil properties (e.g., soil type, texture, and moisture content) and Pi are the most important factors.

Rf usually is inversely related to $\mathrm{Pi}$; therefore, $\mathrm{Rf}$ at different locations can only be compared over a comparable range of Pi. Alternatively, slopes associated with linear relationships between $\mathrm{Rf}$ and $\mathrm{Pi}$ provide a means to evaluate and compare fitness of particular hosts or locations for nematode reproduction. The intercepts of the regression lines can be used to estimate the minimum population densities that must occur to observe the decline in population densities due to competition and/or other density-related factors. Given the same Pi, locations or crops with steeper slopes are likely to have smaller nematode population densities at the end of season. The significant differences in slopes and intercepts between resistant and susceptible cultivars within the same MZ reflected the fact that two host types have different influences on nematode reproduction. In spite of the differences in Pi and Rf among our test sites, slopes and intercepts appeared to be similar among test sites. Comparisons of slopes and intercepts indicated that sites in MZ 1 appeared more homogeneous than those in MZ 2 and 3. The heterogeneity found in MZ 2 and 3 indicates careful monitoring is warranted when management decisions are to be made for soybean production in $H$. glycines-infested fields.

\section{ACKNOWLEDGMENTS}

This research was conducted as part of a grant entitled, "Soybean Cyst Nematode in the North Central Region: Yield Losses and Effects of Management Strategies," from the North Central Soybean Research Program. Additional support was received from the Iowa Soybean Board and the Missouri Soybean Merchandising Council. Authors gratefully acknowledge the technical assistance of S. Souhrada, Iowa State University; Harry L. Minor, University of Missouri; R. S. Lyon, G. M. Sutton, J. B. Eisley, J. R. Jasinski, C. E. Young, Ohio State University; and Edward S. Oplinger, University of Wisconsin. We thank G. F. Krause and M. R. Ellersieck, Department of Statistics, University of Missouri, for advice in statistical analysis.

Table 8. Comparisons of slopes and intercepts derived from regression linear models $(\log 10 \mathrm{Rf}=\operatorname{slope} \times \log 10(\mathrm{Pi}+1)+$ intercept $)$ of tested sites for each host reaction type (resistant and susceptible) within the same maturity zone (MZ) and the same year ${ }^{\mathrm{x}}$

\begin{tabular}{|c|c|c|c|c|c|c|c|}
\hline \multirow[b]{2}{*}{ MZ } & \multirow[b]{2}{*}{ Year } & \multicolumn{2}{|c|}{ Resistant $^{y}$} & \multicolumn{2}{|c|}{ Susceptible } & \multicolumn{2}{|c|}{ Resistant/susceptible $^{\mathrm{z}}$} \\
\hline & & Slope & Intercept & Slope & Intercept & Slope & Intercept \\
\hline 1 & 1994 & $0 / 3$ & $1 / 3$ & $1 / 3$ & $3 / 3$ & S & S \\
\hline 1 & 1995 & $0 / 6$ & $2 / 6$ & $0 / 6$ & $1 / 6$ & NS & $\mathrm{S}$ \\
\hline 2 & 1994 & $4 / 21$ & $10 / 21$ & $4 / 28$ & $10 / 28$ & NS & $\mathrm{S}$ \\
\hline 2 & 1995 & $3 / 28$ & $9 / 28$ & $1 / 45$ & $14 / 45$ & $\mathrm{~S}$ & $\mathrm{~S}$ \\
\hline 3 & 1994 & $3 / 28$ & $17 / 28$ & $2 / 36$ & $19 / 36$ & $\mathrm{~S}$ & $\mathrm{~S}$ \\
\hline 3 & 1995 & $1 / 11$ & $1 / 11$ & $1 / 21$ & $5 / 21$ & $\mathrm{~S}$ & $\mathrm{~S}$ \\
\hline 4 & 1994 & $\ldots$ & $\ldots$ & $\ldots$ & $\ldots$ & NS & $\mathrm{S}$ \\
\hline 4 & 1995 & $\ldots$ & $\ldots$ & $\ldots$ & $\ldots$ & $\mathrm{S}$ & $\mathrm{S}$ \\
\hline
\end{tabular}

${ }^{\mathrm{x}}$ There was only one location in zone $1 . \mathrm{Rf}=(\mathrm{Pf}+1) /(\mathrm{Pi}+1)$, where $\mathrm{Pf}$ is the number of eggs per $100 \mathrm{~cm}^{3}$ of soil at or near harvest, and $\mathrm{Pi}$ is the number of eggs per $100 \mathrm{~cm}^{3}$ of soil at planting.

${ }^{y}$ Regression models derived from resistant or susceptible cultivars at each location within the same maturity zone and the same year are compared. In each maturity zone and each year, the total number of pair comparisons of linear models for slopes and intercepts are indicated by numbers in denominator. Among those pair comparisons, incidences when slopes or intercepts were significantly different $(P=0.05)$ are indicated by numbers in numerator.

${ }^{\mathrm{z}}$ The regression model derived from all pooled resistant cultivars within each maturity zone in each year is compared with the model from all pooled susceptible cultivars. S, NS are significant, not significant $(P=0.05)$, respectively. 
LITERATURE CITED

1. Byrd, D. W., Jr., Barker, K. R., Ferris, H., Nusbaum, C. J., Griffin, W. E., Small, R. H., and Stone, C. A. 1976. Two semiautomatic elutriators for extracting nematodes and certain fungi from soil. J. Nematol. 8:206-212.

2. Doupnik, B., Jr. 1993. Soybean production and disease loss estimates for north central United States from 1989 to 1991. Plant Dis. 77:1170-1171.

3. Edwards, D. I. 1988. The soybean cyst nematode. Pages 81-86 in: Soybean Diseases of the North Central Region. T. D. Wyllie and D. H. Scott, eds. American Phytopathological Society, St. Paul, MN.

4. Francl, L. J. 1986. Improving the accuracy of sampling field plots for plant-parasitic nematodes. J. Nematol. 18:190-195.
5. Hill, N. S., and Schmitt, D. P. 1989. Influence of temperature and soybean phenology on dormancy induction of Heterodera glycines. J. Nematol. 21:361-369.

6. Koenning, S. R., Schmitt, D. P., and Barker, K. R. 1996. Soybean maturity group and planting date effects on seed yield and population densities of Heterodera glycines. Fundam. Appl. Nematol. 19:135-142.

7. Niblack, T. L., ed. 1993. Protect your soybean profits: Manage soybean cyst nematode. American Soybean Association. University of Missouri, Columbia.

8. Niblack, T. L., Heinz, R. D., Smith, G. S., and Donald, P. A. 1993. Distribution, density, and diversity of Heterodera glycines in Missouri. Suppl. J. Nematol. 25:880-886.

9. Noel, G. R., and Sikora, E. J. 1990. Evaluation of soybeans in maturity groups I-IV for resistance to Heterodera glycines. Suppl. J. Nematol. 22:795-799.

10. Riggs, R. D., Schmitt, D. P., and Noel, G. R 1988. Variability in race tests with Heterodera glycines. J. Nematol. 20:565-572.

11. Schmitt, D. P. 1991. Management of Heterodera glycines by cropping and cultural practices. J. Nematol. 23:348-352.

12. Todd, T. C. 1993. Soybean planting date and maturity effects on Heterodera glycines and Macrophomina phaseolina in Southeastern Kansas. J. Nematol. 25:731-737.

13. Workneh, F., Tylka, G. L., Yang, X. B., Faghihi, J., and Ferris, J. M. 1999. Regional assessment of soybean brown stem rot, Phytophthora sojae, and Heterodera glycines using area-frame sampling: Prevalence and effects of tillage. Phytopathology 89:204 211. 